\title{
Study of Cervical Pap Smears in a Tertiary Hospital
}

\author{
Dr. Samta Bali Rathore ${ }^{1}$, Dr. Ranjana Atal ${ }^{2}$
}

${ }^{1}$ MBBS, MS, Associate Professor, Department of Obstetrics And Gynaecology, Mahatma Gandhi Medical College and Hospital , Sitapura, Jaipur

${ }^{2}$ MBBS, MS, Senior Resident, Department of Obstetrics and Gynaecology, Mahatma Gandhi Medical College and Hospital, Sitapura, Jaipur

\begin{abstract}
Background: Cancer of the cervix is the leading cancer among females of india. Cancer of cervix is readily preventable, and can be diagnosed at the pre-invasive stage with adequate and repetitive cytological screening with Papanicolaou (Pap )smears. Objectives: This is a retrospective study aimed to evaluate all previously conducted cervical smears examined at a teaching tertiary hospital during a six month period. Methods: Detailed clinical data and Pap smear cytology reports were obtained and data noted in a structured proforma. All the smears were reported as per the 2001 Bethesda system. Results: A total of 500 Pap smears were examined. Maximum number of patients was in the age group of $31-40$ years (fourth decade). There were 37(7.4\%) unsatisfactory or inadequate samples . A total of 430 smears were reported as Negative for Intraepithelial Lesion or Malignancy (NILM), of which 60 (12\%) showed normal cytological findings and 370(74\%) were inflammatory. Out of a total of 500 Pap smears, only 33(6.6\%\%) cases were reported to have epithelial cell abnormality. The 33 abnormal cases comprised of 20 cases with ASC-US, 8 cases of LSIL, 2 cases of HSIL, 2 cases of invasive squamous cell carcinoma, and one case of adenocarcinoma cervix. Conclusion: Premalignant and malignant lesions of cervix can be diagnosed easily by Pap smears. The epithelial cell abnormality rate in our study was $6.6 \%$.
\end{abstract}

Keywords: cervical cytology, pap smear, screening, squamous intraepithelial lesion (SIL)

\section{Introduction}

Cervical cancer is the second most common cancer in women worldwide after breast cancer, and in developing countries, the leading cause of death by cancer ${ }^{1}$. Cervical cancers in the early stage of development, or carcinomas in situ, are highly treatable because the cancer cells are located in a layer of cells in or around the cervix and have not spread to other parts of the body. Once the cancer cells metastasize to other parts of the body the disease is more difficult to treat and cervical cancer treatment becomes more complex ${ }^{2}$.

The Papanicolaou (Pap) smear was introduced in 1941 and became the standard screening test for cervical cancer and premalignant lesions ${ }^{3}$. Though pap test plays a stellar role in detection of carcinoma and precancer, its role in diagnosis of infective inflammatory conditions including the identification of causative organism, hormone related benign epithelial changes and changes due to therapeutic agents is no less successful. Originally, the term Pap smear was used for smears made out of posterior fornix material for purpose of detection of cancer and pre-cancer lesions. But presently, the term is used for smear made from material collected from vagina, endocervical canal, ectocervix or vaginal vault ${ }^{4}$. The randomized examination of cervical PAP smears in women with vaginal discharge showed that cervical infections, intra epithelial neoplasia of various grade and invasive cervical carcinoma are much more common in India as compared to the Western countries. The possible reason for this fact is the absence of cervical screening program, low social-economic status, and lack of awareness of cervical cancer prevention by PAP smears ${ }^{5}$. The simplicity, effectiveness and versatility of Pap test have made it an integral part of routine clinical examination and large chunk of workload in gynecological and pathological practice is due to this test ${ }^{6}$.

Cancer of uterine cervix is a leading cause of mortality and morbidity among women worldwide.Usually $70 \%$ or more of these cases present in stage 3 or higher at the time of diagnosis ${ }^{7}$. It is estimated that in India 126,000 new cases of cervical cancer occur annually ${ }^{8}$. Cancer of cervix is readily preventable as it is easy to detect and treat its precursor lesions ${ }^{9}$. Papanicolaou cytological (Pap) test, since its introduction, has been boon, as dramatic reduction has been observed in the incidence and mortality of invasive cervical cancer worldwide ${ }^{10}$. This is because the Pap test detects cervical epithelial cell abnormalities which represent a spectrum of intraepithelial lesions, from mild-to-severe dysplasia to invasive cancer ${ }^{11}$ and facilitates early diagnosis.

\section{Aims and Objectives}

The aim of our study is to evaluate the

1) To explore various leisons of uterine cervix \{ inflammatory and growth\}

2) To find out target age group in which screening efforts can be concentrated for early detection as well as reduction of incidence of cervical cancer, in our setup.

\section{Material and Methods}

In this study we have conducted Pap test in female at Mahatma Gandhi Medical College and Hospital, Sitapura Jaipur that voluntarily consented to undergo this test.

Study Design - retrospective Study.

Study Period - August 2015 to January 2016

Place of study - OBGY Department of Mahatma Gandhi Medical College and Hospital, Sitapura Jaipur

Sample Size - 500 females

Sampling Technique is systemic random sampling.

All sexually active women coming to gynaecology OPD between the ages of 21 to 60 years consenting for Pap smear were included in the study. Those who presented with excessive white discharge per vagina, bleeding per vagina, irregular menstruation, pelvic pain and dysparerunia were

\section{Volume 5 Issue 5, May 2016}




\section{International Journal of Science and Research (IJSR) \\ ISSN (Online): 2319-7064 \\ Index Copernicus Value (2013): 6.14 | Impact Factor (2015): 6.391}

considered as symptomatic.

Before taken pap smear, it was ensured that no local douche, antiseptic cream and no local internal examination was done on day of test. The patient was placed in dorsal lithotomy position and a Cusco's bivalve speculum was introduced through vagina and cervix was visualized. The longer projection of the Ayre's spatula was placed in the cervix near squamo-columnar junction and rotated through 360 degree $^{12}$. The cellular material thus obtained was quickly, but gently smeared on a clean glass slide. Two smears were prepared for each case. The glass slide was then immediately put into the coplin jar containing 95\% ethyl alcohol (fixative), stained by Papanicolaou stain. The cytological interpretation of smears was made under light microscope according to the New Bethesda System 2001. The epithelial cell abnormalities particularly the squamous epithelial abnormality has been categorized into atypical squamous cells(ASC) including ASC of undetermined significance (ASC-US) and ASC, cannot exclude high grade squamous intraepithelial lesions (ASCH )and squamous intra epithelial lesion (SIL). SIL was again subdivided into low-grade squamous intraepithelial lesion(LSIL) and high-grade squamous intraepithelial lesion(HSIL). Frank invasive malignancy was termed as squamous cell carcinoma. Similarly, glandular cell abnormalities were categorized into atypical endocervical cells not otherwise specified, atypical endometrial cell not otherwise specified and atypical glandular cell not otherwise specified. Those with LSIL andHSIL were counselled and were advised to undergo colposcopic examination and biopsy for histopathological examination.

\section{Result}

A total of 500 cases were analysed during a period of six months. The age of women ranged from 21 to 60 years with an average age of 36 years. Most of the women were in age group $31-40$ years (table 1 ).

Table 1: Age wise distribution of total number of patients

\begin{tabular}{|c|c|c|}
\hline Age group(years) & No. of cases & Percentage \\
\hline $21-30$ & 84 & $16.80 \%$ \\
\hline $31-40$ & 218 & $43.60 \%$ \\
\hline $41-50$ & 136 & $27.20 \%$ \\
\hline $51-60$ & 62 & $12.40 \%$ \\
\hline Total & 500 & 100 \\
\hline
\end{tabular}

As per as the patients presenting complain was concerned, vaginal discharge was commonest $(52.7 \%)$ followed by lower abdominal pain (39.0\%) and postmenopausal bleeding (7.3\%).Among those who underwent Pap testing,261 $(52.2 \%)$ cases were asymptomatic and the remaining cases 239(47.8\%) were symptomatic(table 2). Among subjects aged 30 years and below, none had positive result irrespective of symptom status.There were 136 (27.2\%) subjects who belonged to the age group between 41-50 years. Among them, 40 were asymptomatic and 96 were symptomatic. Pap smear was positive in this age group in 29 subjects.3 pap smears were positive in age group 5160years.
Table 2: Comparison of yield of positive and negative pap smears in various age groups

\begin{tabular}{|c|c|c|c|c|}
\hline $\begin{array}{c}\text { Age } \\
\text { (years) }\end{array}$ & $\begin{array}{c}\text { Symptomatic } \\
\text { status }\end{array}$ & $\begin{array}{c}\text { Pap } \\
\text { smear } \\
\text { negative }\end{array}$ & $\begin{array}{c}\text { Pap } \\
\text { smear } \\
\text { positive }\end{array}$ & Total \\
\hline \multirow{2}{*}{$21-30$} & Symptomatic & 36 & 0 & 36 \\
\cline { 2 - 5 } & Asymptomatic & 48 & 0 & 48 \\
\hline \multirow{2}{*}{$31-40$} & Symptomatic & 63 & 0 & 63 \\
\cline { 2 - 5 } & Asymptomatic & 154 & 1 & 155 \\
\hline \multirow{2}{*}{$41-50$} & Symptomatic & 83 & 13 & 96 \\
\cline { 2 - 5 } & Asymptomatic & 24 & 16 & 40 \\
\hline \multirow{2}{*}{$51-60$} & Symptomatic & 42 & 2 & 44 \\
\cline { 2 - 5 } & Asymptomatic & 17 & 1 & 18 \\
\hline
\end{tabular}

The Pap smears were adequate and there was no other nonneoplastic or glandular cell abnormality noted apart from epithelial cell abnormality in $33(6.6 \%)$ of the cases. All other smears were either within normal limit or mild acute inflammatory cell infiltration. 37(7.4\%) smears were found to be unsatisfactory for evaluation. The negative for intraepithelial lesion category has the following findings: normal $60(12 \%)$ cases,nonspecific inflammation 360(72\%) cases, Trichomonas infection $3(0.6 \%)$ cases , Candidiasis $7(1.4 \%)$ cases. The 33 abnormal cases comprised of $20(4 \%)$ cases with ASC-US, 8(1.6\%) cases of LSIL, 2(0.4\%) cases of HSIL, $2(0.4 \%)$ cases of invasive squamous cell carcinoma and $1(0.2 \%)$ case of adenocarcinoma cervix. So most frequent epithelial cell abnormality cytologically was ASCUS (20) in our study.

Table 3: Findings of pap smear cytology

\begin{tabular}{|c|c|c|c|c|}
\hline \multicolumn{2}{|c|}{ Diagnosis } & $\begin{array}{c}\text { No. of } \\
\text { cases }\end{array}$ & Percentage \\
\hline \multirow{3}{*}{$\begin{array}{c}\text { Unsatisfactory } \\
\text { smears }\end{array}$} & \multicolumn{2}{|c|}{ Inadequate sample } & 37 & $7.40 \%$ \\
\cline { 2 - 5 } & \multicolumn{2}{|c|}{ Obscured with blood } & 27 & $5.40 \%$ \\
\hline \multirow{3}{*}{ NILM } & Normal & & 430 & $2.00 \%$ \\
\cline { 2 - 5 } & Inflammatory & Non-specific & 360 & $72.00 \%$ \\
\cline { 2 - 5 } & & Candida & 7 & $1.40 \%$ \\
\cline { 2 - 5 } & & Trichomonas & 3 & $0.60 \%$ \\
\hline ASCUS & & & 20 & $4.00 \%$ \\
\hline LSIL & & & 8 & $1.60 \%$ \\
\hline HSIL & & & 2 & $0.40 \%$ \\
\hline \multirow{2}{*}{$\begin{array}{c}\text { Squamous cell } \\
\text { carcinoma }\end{array}$} & & & 2 & $0.40 \%$ \\
\hline AGCUS & & & 0 & $0.00 \%$ \\
\hline Adenocarcinoma & & & 1 & $0.20 \%$ \\
\hline Total & & & 500 & $100 \%$ \\
\hline
\end{tabular}

\section{Discussion}

With the changes in the life styles and demographic profiles in developing countries, non communicable diseases are emerging as an important health problem which demand appropriate control program before they assume epidemic propagation. The incidence of cervical cancer has decreased more than $50 \%$ in the past 30 years because of widespread screening with cervical cytology. In India incidence rates of cancer of the cervix is very high especially in rural areas. The age-standardized incidence rates have ranged from 16-55 per 100,000 women in different regions of India ${ }^{8}$. Although control of cervical cancer by early detection and treatment remains a priority of the National Cancer Control 


\section{International Journal of Science and Research (IJSR) \\ ISSN (Online): 2319-7064}

Index Copernicus Value (2013): 6.14 | Impact Factor (2015): 6.391

Programme of India, organized cytology screening programmes are definitely lacking. One possible reason is the technical and financial constraints to organize cytology screening ${ }^{8}$.

Cervical cytology is currently widely used as the most effective cancer screening modality. Objective data from hospital-based studies are required in order to detect the efficiency of the screening test. This study contributes to assessing current levels of cervical screening in the tertiary teaching hospital in Jaipur, India.

In our study, the mean age of patients with abnormal smears was 36 years. Vaginal discharge was the most common presenting complaint in our study.

This study determines 430 cases $(86 \%)$ of negative for intraepithelial lesion or malignancy with non-specific inflammation 360 cases $(72 \%)$ as the pre-dominant one. Other studies revealed $95 \%$ and $74.3 \%$ cases of NILM respectively ${ }^{14}$.The Epithelial Cell Abnormality (ECA) rate, that is the total of ASCUS, LSIL,HSIL, and carcinoma diagnosis varied between 1.5 and $12.60 \%$ in various studies. The ECA rate of $6.6 \%$ in our study was comparable to those reported in literature. In a study ${ }^{15}$ conducted at a tertiary care hospital in Kuwait, prevalence of cervical cell abnormality in Pap smear was found to be $4.3 \%$. A recent study ${ }^{16}$ conducted in Ningen Dock, Japan aimed to determine the gynaecological status of asymptomatic women who attended the hospital for health check-up, showed a low prevalence cervical cell abnormalities of $1.2 \%$. The explanation behind this result is mostly because of their cultural traditions and great concern regarding their health check-ups and less likelihood of having multiple sexual partners.

Our study revealed ASCUS 20(4\%) to be the most common epithelial cell abnormality. Similar results were obtained in other studies which also concluded ASCUS to be the most common epithelial cell abnormality ${ }^{17}$. In our study $1.60 \%$ had Low-grade Squamous Intraepithelial Lesion (LSIL), and $0.40 \%$ had high-grade

Squamous Intraepithelial Lesions (HSIL). In contrast, Study ${ }^{18}$ from Saudi Arabia had varied results, $4.9 \%$ of cases were diagnosed with SIL. Our study thus elucidates the importance of Papanicolaou cervical screening test. Community health awareness campaigns and large scale Pap screening programmes for women should be undertaken.

\section{Conclusion}

Cervical cancer is one of the most common malignancies in women of developing country like India. Pap smear is a simple, cheap, safe and practical diagnostic tool for early detection of cervical cancer in high risk group population, so it should be established as a routine screening procedure. It also has a greater role in diagnosis of inflammatory lesions including the identification of causative organism, atrophic changes, changes of radiation therapy and some rare tumors. It is recommended that at least a single life-time pap screening cytology of uterine cervix of all the women aged 40 to 50 years.

\section{References}

[1] National Cancer Regitry Program. Annual Report. IC New Delhi; 1990-1996.

[2] Papanicolaou, GN, Traut, HF. The diagnostic value of vaginal smears in carcinoma of the uterus. Am Jr Obstet Gynecol 1941; 42:193-205.

[3] Mintzer M, Curtis P, Resnick JC, Morrell D. The effect of the quality of Papanicolaou smears on the detection of cytologic abnormalities

[4] Cancer 1999; 87:113-7.

[5] Anderson and Jones: false positive cervicovaginal cytology. acta cytol 41(6):267,1997.

[6] George Burkadze, Gulisa Turashvili: Cytology interpretations of cervical Pap smears in Georgia. The Internet Journal of Gynecology and Obstetrics. 2004; 3:2.

[7] K.Park: Test book of preventive and social medicine, 18th edi.2005; page no304-305.

[8] Nandakumar A, Anantha N, Venugopal TC.Incidence, mortality and survival in cancer of the cervix in Bangalore, India. Br J Cancer 1995;71:1348-52.

[9] Sankaranarayanan R, Nene BM, Dinshaw K, Rajkumar R, Shastri S, Wesley R, et al. Early detection of cervical cancer with visual inspection methods: a summary of completed and ongoing studies in India. Salud Publica Mex 2003;45:S399- 407.

[10]Bal MS, Goyal R, Suri AK, Mohi MK. Detection of abnormal cervical cytology in Papanicolaou smears. J Cytol 2012;29:45-7.

[11] Afrakhteh M, Khodakarami N, Moradi A, Alavi E, Shirazi FH. A study of 13315 papanicolaousmear diagnoses in Sohada hospital. J Fam Reprod Health 2007;1:75-9.

[12] Banik U, Bhattacharjee P, Ahamad SU, Rahman Z. Pattern of epithelial cell abnormality in Pap smear: A clinicopathological and demographic correlation. Cytojournal 2011;8:8.

[13] Banik U, Bhattacharjee P, Ahamad SU, Rahman Z. Pattern of epithelial cell abnormality in Pap smear: A clinicopathological and demographic correlation. Cytojournal 2011; 8:8.

[14] Solomon D, Davey D, Kurman R, Moriarty A, O'Connor D, Prey M, et al.The

[15] 2001 Bethesda System: terminology for reporting results of cervical cytology. JAMA 2002; 287:2114-9.

[16] 14. Ranabhat, S. K., Shrestha, R., Tiwari, M. Analysis of abnormal epithelial lesions in cervical Pap smears in Mid-Western Nepal. Journal of Pathology of Nepal 1,30 -33, 2011.

[17] Kapila K, George SS, Al-Shaheen A, Al-OttibiMS, Pathan SK, Sheikh ZA,et al. Changing spectrum of squamous cell abnormalities observed on papanicolaou smears in Mubarak Al-Kabeer Hospital, Kuwait, over a 13-year period. Med Princ Pract 2006;15:253-9.

[18] Imai A, Matsunami K, Takagi H, Ichigo S. Trend of Incidence in Positive Cervical Smears from 2002 - 2010 in Ningen Dock, a Special Japanese Health Checkup System. Ningen Dock 2012;26:923-6.

[19] Ghaith J.E., Rizwana B.S. - Rate of Opportunistic Pap smear Screening and Patterns of Epithelial Cell Abnormalities in Pap Smears in Ajman, United Arab 


\section{International Journal of Science and Research (IJSR) \\ ISSN (Online): 2319-7064}

Index Copernicus Value (2013): 6.14 | Impact Factor (2015): 6.391

[20] Emirates. Sultan Qaboos Univ Med J; 12(4): 473-478, 2012.

[21]Elhakeem HA, Al- Ghamdi AS, Al-Maghrabi JA.

Cytopathological pattern of cervical Pap smear according to the Bethesda system in Southwestern Saudi Arabia. Saudi Med J 2005;26:588-92. 